KAPL-2006

AEC Research and Development Report

Knolls

Atomic Power Laboratory

UNIVERSITY OF

TARIZONA. LIBRARY

Documents Collection उय 151959

\title{
Transistorized Log-Period Amplifier
}

\author{
E. J. Wade \\ D. S. Davidson
}

Operated for the

United States Atomic

June, 1959

Energy Commission by 



\section{KAPL-2006}

UC-37, Instruments

(TID-4500, 14th Edition)

\section{TRANSISTORIZED LOG-PERIOD AMPLIFIER}

E. J. Wade, D. S. Davidson

June, 1959
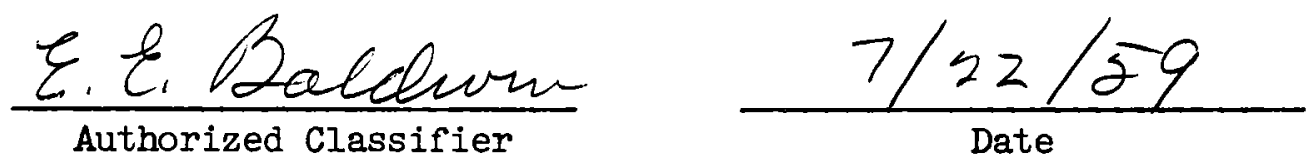

General Electric Company

KNOLIS ATOMIC POWER IABORATORY

Schenectady, New York

Operated for the

United States Atomic Energy Commission

Contract No. W-31-109 Eng-52 
IEGAL NOTICE

This report was prepared as an account of Government sponsored work. Neither the United States, nor the Commission, nor any person acting on behalf of the Commission:

A. Makes any warranty or representation, expressed or implied, with respect to the accuracy, completeness, or usefulness of the information contained in this report, or that the use of any information, apparatus, method, or process disclosed in this report may not infringe privately owned rights; or

B. Assumes any liabilities with respect to the use of, or for damages resulting from the use of any information, apparatus, method, or process disclosed in this report.

As used in the above, "person acting on behalf of the Commission" includes any employee or contractor of the Commission, or employee of such contractor, to the extent that such employee or contractor of the Commission, or employee of such contractor prepares, disseminates, or provides access to, any information pursuant to his employment or contract with the Commission, or his employment with such contractor.

Printed in USA. Price $\$ 0.75$. Available from the Office of Technical Services, Department of Commerce, Washington 25, D. C. 
Internal Distribution

\author{
KAPL-2006 \\ UC-37, Instmuments \\ (TID-4500, 14th Edition) \\ No. of Copies
}

AEC, SNROO

Anderson, JD

Bistline, JA

1

Childs, JC

Clairmont, PL

Davidson, DS

Document Library

Edwards, RA

Eisenacher, $P$

Faught, RC

Fehr, EB

Franke, JS

Frost, RT

King, JS

Kitchen, SW

La Violette, FG

Livingston, $R$

Luce, RG

Lynch, DC

Mackeown, RC

Rohr, RC

Schultz, H

Sears, MJ

Shea, RF

Speck, RG

Stack, D

1

1

1

1

1

4

1

1

1

1

1

1

1

1

1

1

1

1

1

1

1

1

1

1

1

Wade, EJ

20

External Distribution

Aberdeen Proving Ground

Aerojet-General Corporation

Aerojet-General, San Ramon (100-880)

AFPR, Boeing, Seattle

1

AFPR, Lockheed, Marietta

Air Force Special Weapons Center

ANP Project Office Convair, Fort Worth

Alco Products, Inc.

Argonne Cancer Research Hospital 
$\underline{\text { KAPL-2006 }}$

External Distribution (continued)

No. of Copies

Argonne National Laboratory

10

Armed Forces Special Weapons Project, Washington

Armed Services Technical Information Agency

Army Ballistic Missile Agency

Army Chemical Center

Army Signal Research and Development Laboratory

Atomic Bomb Casualty Commission

AEC Scientific Representative, Japan

Atomic Energy Commission, Washington (TI)

Atomics International

Babcock and Wilcox Company (NYOO-1940)

Battelle Memorial Institute

Bettis Plant

Brookhaven National Laboratory

Bureau of Medicine and Surgery

Bureau of Mines, Salt Lake City

Bureau of Ships (Code 1500)

Carnegie Institute of Technology

Chicago Operations Office

Chicago Patent Group

Columbia University (Failla)

Columbia University (Havens)

Combustion Engineering, Inc.

Convair-General Dynamics Corporation, San Diego

Defense Research Member

Department of the Army, G-2

Division of Raw Materials, Austin

Division of Raw Materials, Denver

Division of Raw Materials, Grants Branch

Division of Raw Materials, Salt Lake City

Dow Chemical Company (Rocky Flats)

duPont Company, Aiken

duPont Company, Wilmington

Edgerton, Germeshausen and Grier, Inc., Boston

Edgerton, Germeshausen and Grier, Inc., Las Vegas

Frankford Arsenal

General Electric Company (ANPD)

General Electric Company, Richland

General Nuclear Engineering Corporation 
KAPL-2006

External Distribution (continued)

No. of Copies

Goodyear Atomic Corpration

Grand Junction Operations Office

1

Hawaii Marine Laboratory

1

Iowa State College

Jet Propulsion Laboratory

1

Los Alamos Scientific Laboratory

Lovelace Foundation

Mallinckrodt Chemical Works

Maritime Administration

Martin Company

Mound Laboratory

National Advisory Conmittee for Aeronautics, Cleveland

National Bureau of Standards

National Bureau of Standards (Library)

National Lead Company of Ohio

Naval Medical Research Institute

Naval Research Laboratory

New Brunswick Area Office

New York Operations Office

Nuclear Development Corporation of America

Nuclear Metals, Inc.

Oak Ridge Institute of Nuclear Studies

Office of Naval Research

Office of Naval Research (Code 422)

Office of Ordnance Research

Office of the Surgeon General

Ordnance Materials Research Office

1

Ordnance Tank-Automotive Command

Patent Branch, Washington

Phillips Petroleum Company (NRTS)

Picatinny Arsenal

Power Reactor Development Company

Pratt and Whitney Aircraft Division

Princeton University (White)

Public Health Service

Public Health Service, Savannah

Sandia Corporation, Albuquerque

Technical Research Group

Tennessee Valley Authority

The Surgeon General

Union Carbide Nuclear Company (ORGDP) 


\begin{tabular}{|c|c|}
\hline & KAPI-2006 \\
\hline External Distribution (continued) & No. of Copies \\
\hline Union Carbide Nuclear Company (ORNL) & 5 \\
\hline Union Carbide Nuclear Company (Paducah Plant) & 1 \\
\hline USAF Project RAND & 1 \\
\hline U. S. Geological Survey, Denver & 1 \\
\hline U. S. Geological Survey, Menlo Park & 1 \\
\hline U. S. Geological Survey, Naval Gun Factory & 1 \\
\hline U. S. Geological Survey, Washington & 1 \\
\hline U. S. Naval Postgraduate School & 1 \\
\hline U. S. Naval Radiological Defense Laboratory & 2 \\
\hline U. S. Patent Office & 1 \\
\hline UCLA Medical Research Laboratory & 1 \\
\hline University of California Medical Center & 1 \\
\hline University of California Radiation Laboratory, Berkeley & 2 \\
\hline University of California Radiation Laboratory, Livermore & 2 \\
\hline University of Chicago, USAF Radiation Laboratory & 1 \\
\hline University of Puerto Rico & 1 \\
\hline University of Rochester & 1 \\
\hline University of Rochester (Marshak) & 1 \\
\hline University of Utah & 1 \\
\hline University of Washington (Geballe) & 2 \\
\hline University of Washington (Rohde) & 1 \\
\hline Vitro Engineering Division & 1 \\
\hline Walter Reed Army Medical Center & 1 \\
\hline Watertown Arsenal & 1 \\
\hline Western Reserve University & 1 \\
\hline Westinghouse Electric Corporation (Schafer) & 1 \\
\hline Wright Air Development Center & 11 \\
\hline Yankee Atomic Electric Company & 1 \\
\hline Technical Information Service Extension & 325 \\
\hline Office of Technical Services, Washington & 100 \\
\hline Total & $\overline{672}$ \\
\hline
\end{tabular}




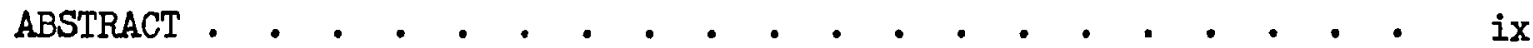

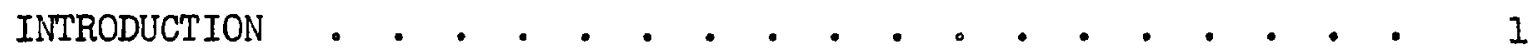

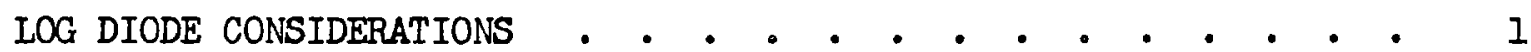

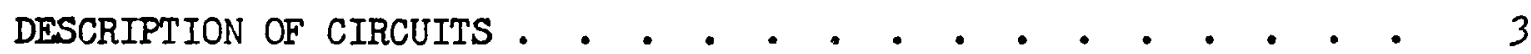

Log Amplifier • • • • • • • • • • • • • • • • 3

Period Amplifier . . . . . . . . . . . . . . . 5

Noise Filters . • . . • . . . . . . . . . . . 7

Catching Circuits . . . . . . . . . . . . . 7

Trip Output . . . . . . . . . . . . . . . . 11

Remote Output and Recorder Circuits . . . . . . . . . 11

Construction - . . . . . . . . . . . . . . . . 11

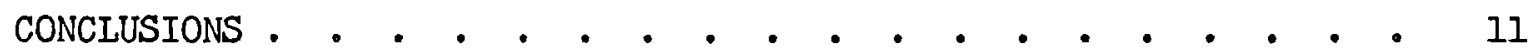

\section{ILIUSTRATIONS}

No.

1 Log-Period Meter - Front View . . . . . . . . . . 2

2 Log Diode Compensation . . . . . . . . . . . . . 2

3 Log Amplifier . . . . . . . . . . . . . . . . 4

4 Period Calibration . . . . . . . . . . . . . . . 4

5 Reset • . • . . . . . . • . . • • . . . 5

6 Period Meter . . . . . . . . . . . . . . . 5

7 Period Amplifier . . . . . . . . . . . . . 6

8 Noise Filter - Catching Circuits and Trip Output . • . . 7

9 Log Period Meter - Bottom View . . . . . . . . . 8

10 Plug-in Circuit Cards . . . . . . . . . . . . 8

11 Transistorized Log-Period Amplifier . • . . . • . . . 9 



\section{ABSTRACT}

A log-period amplifier which is combined with power supply on a rack-mounted chassis with a 7-in. panel is described. The circuits are transistorized except for electrometer tubes and $10 \mathrm{~g}$ diodes. Input power is 25 watts. Noise reducing and calibrating circuits as well as a catching circuit to keep the log diode in its logarithmic range are built into the amplifier. 



\title{
TRANSISTORIZED LOG-PERIOD AMPLIFIER
}

\author{
E. J. Wade, D. S. Davidson
}

\section{INTRODUCTION}

Logarithmic and period amplifiers are well-known and have been found to be indispensable in the operation of reactors because of the wide range covered without any switching being necessary. The period meter measures the exponential rate of increase of power and provides a trip signal if a predetermined rate is exceeded.

This paper is concerned with the application of transistors to the logarithmic amplifier which was described in a paper on the same subject at the 1954 Institute of Radio Engineers convention in New York. ${ }^{1}$

To review the background very briefly, we may say that the current from an ion chamber which is due to the neutron flux is proportional to power. If this current is measured logarithmically, a wide range can be covered with an accuracy which is constant at all levels. The period is defined as the reciprocal of the derivative of the logarithm of current. It is a measure of the e-folding time and is sometimes expressed in terms of doubling time.

The logarithmic amplifier described depends on the use of a thermionic diode as a nonlinear element. Other methods are available which have been described in the literature. 2,3

The use of transistors has allowed the $\mathrm{log}$ and period amplifiers to be combined, together with the power supply, on a single chassis with a 7-in. panel. The weight is only $20 \mathrm{lb}$ and the power input 25 watts. A front view is shown in Figure 1. Operational improvements have been made which will be described.

\section{LOG DIODE CONSIDERATIONS}

The log diode is a nonlinear element with characteristics described by the equation

$$
v=\frac{k T}{e} \log i+b,
$$




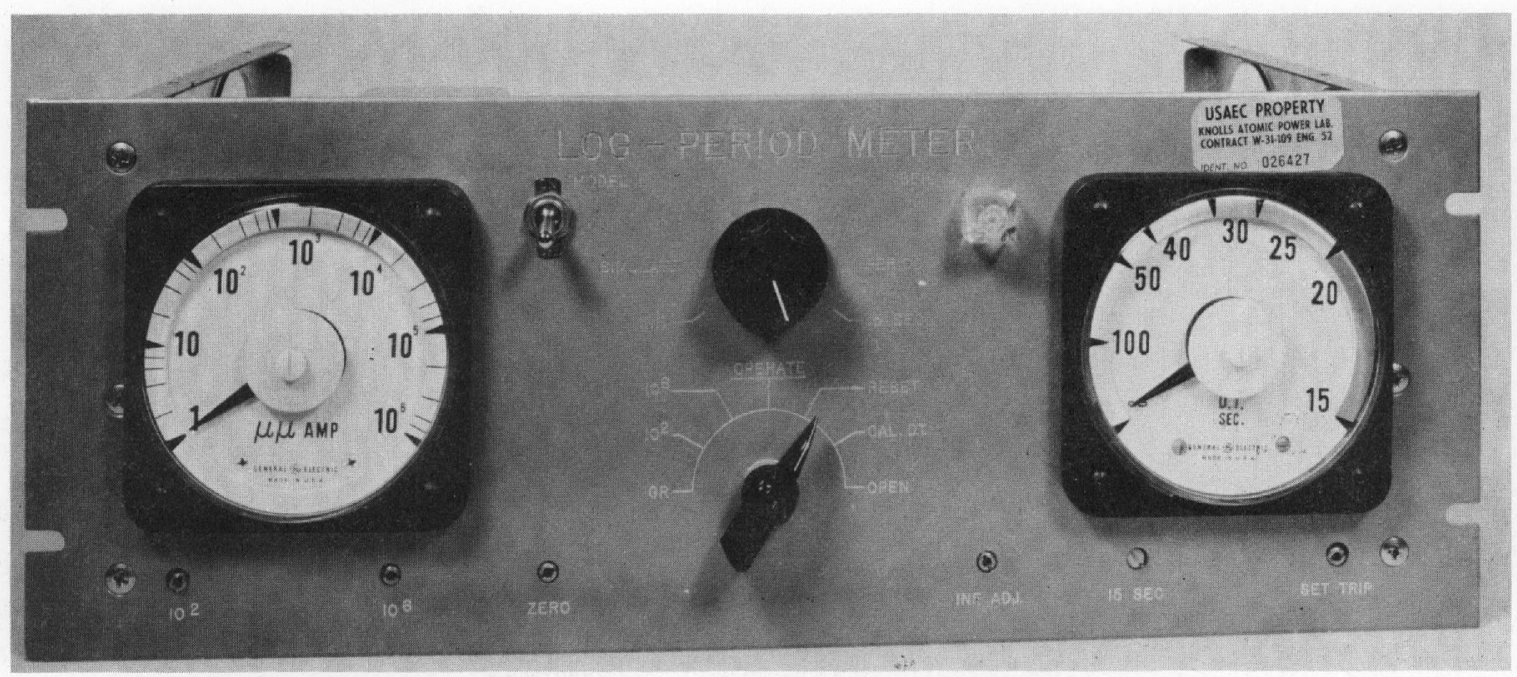

FIGURE 1. Log-Period Meter - Front View

KS-21290

Unclassified

where

$$
\begin{aligned}
& \mathbf{k}=\text { Boltmann's constant } \\
& \mathbf{e}=\text { electronic charge } \\
& \mathbf{T}=\text { cathode temperature, and } \\
& \mathbf{b}=\mathbf{a} \text { constant depending on temperature. }
\end{aligned}
$$

This relationship is theoretically ideal but is sensitive to changes in cathode temperature which introduce a bias and also change the slope.

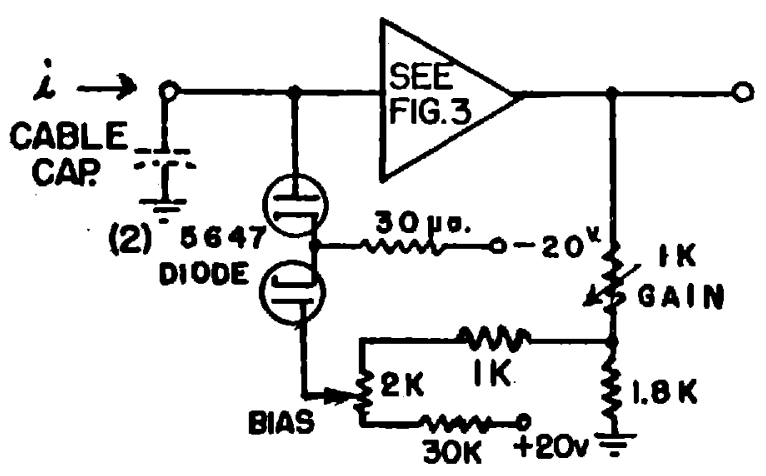

FIGURE 2. Log Diode Compensation
The bias effect can be largely compensated by using two diodes in connections which tend to balance out the effects of temperature changes and power supply variations. Different circuits have been used for this purpose, ${ }^{4}$ but we have chosen to continue to use two diodes in serles back to back, with a constant current through the balance diode which is large compared with the maximum current to be measured (Figure 2). The input curKS-25006(a) rent then flows through both diodes, Unclassified but the change in potential across calibration. The drift is reduced to approximately one-tenth by the compensation, and with regulated heater current it is negligible. 
The diode may be considered as a variable resistance which depends on the current:

$$
R=\frac{k T / E}{i}=\frac{0.1}{i} \text { for constant temperature }
$$

Thus, the resistance will vary one million to one over the operating range of the amplifier, and when used with an input cable of perhaps $1000 \mu \mu f$, it can cause instability when included in the feedback circuit. It has been shown ${ }^{5}$ that overshoot can be avoided if the amplifier amplitude-versus-frequency curve does not exceed $10 \mathrm{db}$ decade, which corresponds to a 45-deg phase shift.

\section{DESCRIPTION OF CIRCUITS}

\section{Log Amplifier}

Low-current electrometer tubes are used for the input stages, since no transistor is available with a sufficiently high input impedance. The most important condition in the use of the electrometers is low grid current, which depends on low plate and screen voltages. With a triode under these low-voltage conditions, the transconductance is only 1.5 times that of the pentode connection, and use of the second grid (screen grid) as a control grid is lost. It is desirable to operate the first control grid in a good region (at least 2 volts negative, so as not to increase grid current, and not more than 3 volts negative, which would reduce the gain unnecessarily). The second grid is useful for controlling the operating conditions of the tubes.

The transistor circuit used is shown in Figure 3. The balanced 5886 subminiature tubes drive a differential stage by using 2 N328 silicon transistors to obtain low $I_{C O}$ and to minimize temperature effects. A stable operating level is obtained without adjustments by connecting the electrometers as tetrodes and supplying the screen currents from the common emitters of the transistors. The plates of the electrometers connect to the bases of the transistors.

With this connection changes in dc level are highly degenerated without reduction of signal gain. Generally, the way the circuit operates is to tend to maintain the total plate currents (the sum of the two) constant. This circuit is better than the triode-connected tubes because of the current gain of the transistors in the differential amplifier. Less current change at the plates is able to control more current at the screens, and because of this gain the result is greater stability. A similar circuit is familiar in vacuum tube practice.

The current output of the differential stage is amplified further by two cascaded emitter-follower stages, which results in an average over-all 


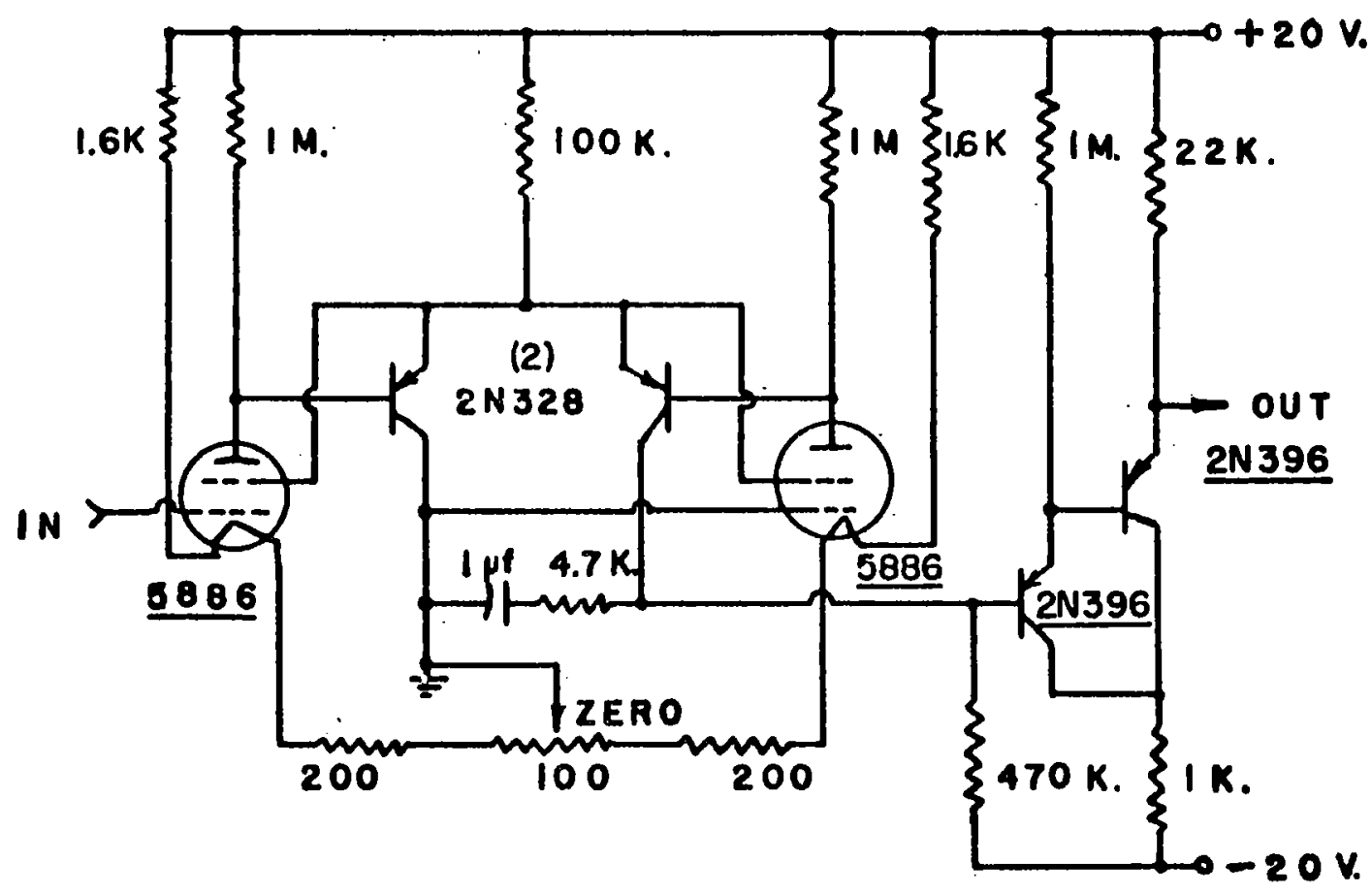

FIGURE 3. Log Amplifier

KS-25005

Unclassified

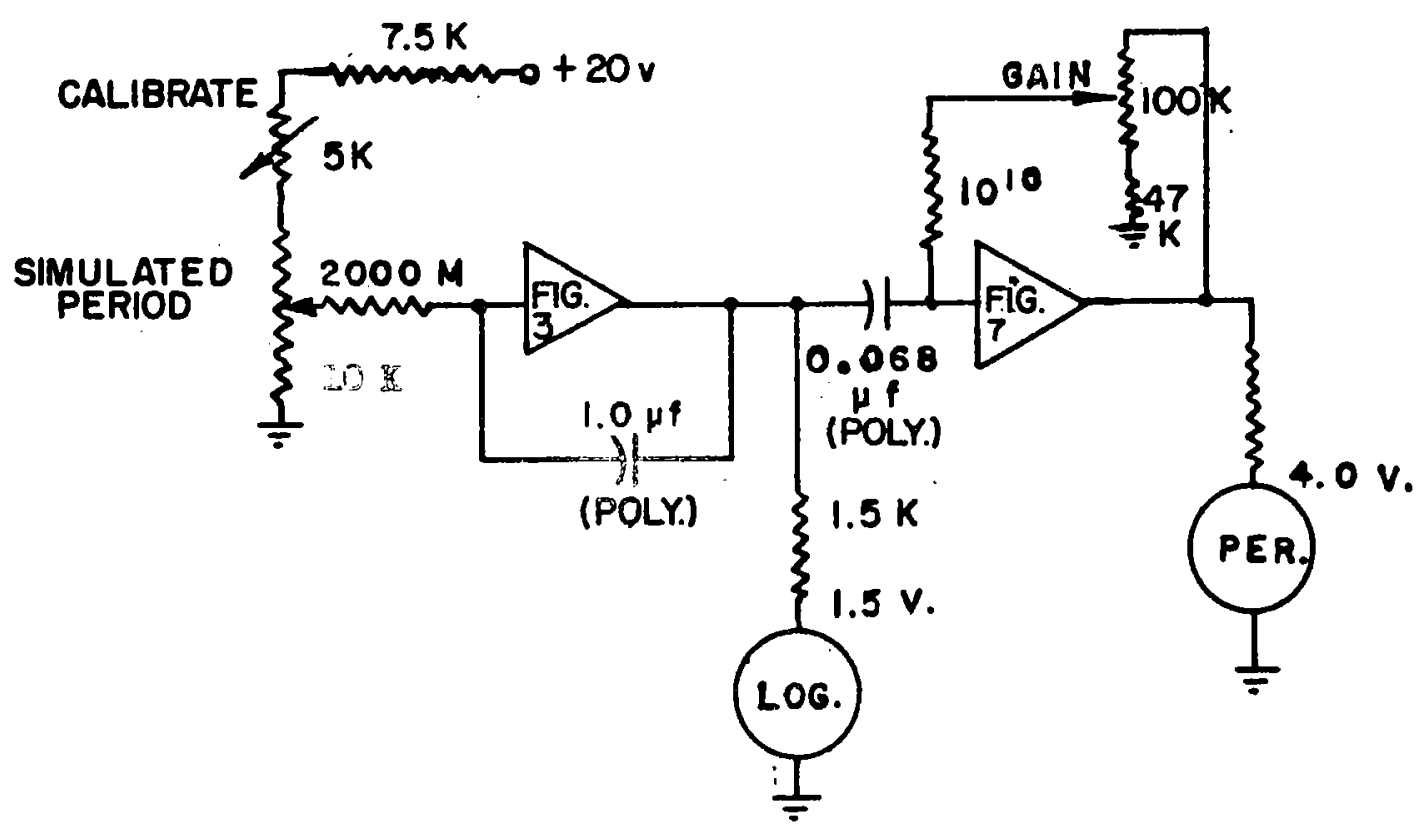

FIGURE 4. Period Calibration 
loop voltage gain of 80 . This was considered adequate for the transient response desired, and higher gain would require additional phase correction and make the circuit more susceptible to noise and pickup.

Calibration of the log amplifier is done in the conventional manner, adjusting for two points, 1.e., $10^{-10}$ and $10^{-6} \mathrm{amp}$, by varying the bias and gain. Adjusting the bias and gain allows the full-scale output to be set for 1.5 , i.e., 0.25 volt/decade or 0.075 volt/octave.

For period calibration (Figure 4) the log diode is biased to be nonconducting and the log amplifier is connected as an integrating amplifier to generate a linear ramp. In order to discharge the capacitors quickly, a reset position (Figure 5) is provided on the function switch which connects feedback resistors of $100 \mathrm{~K}$ and $22 \mathrm{M}$ around the amplifiers. This discharges the ramp generator with a time constant of 0.1 sec and the differentiating capacitor in about 1 sec.

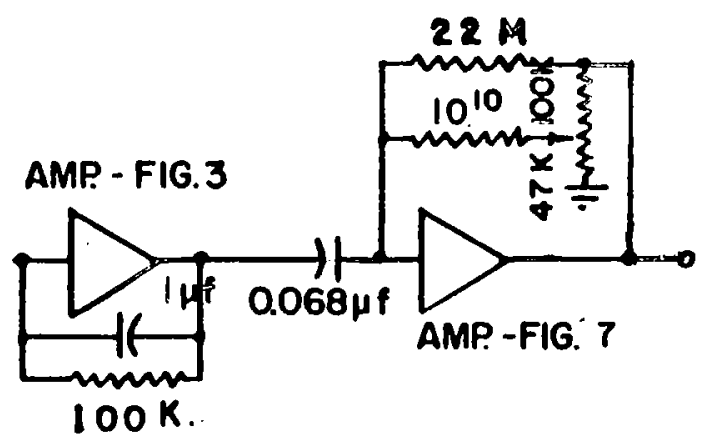

FIGURE 5. Reset

KS-25009

Unclassified

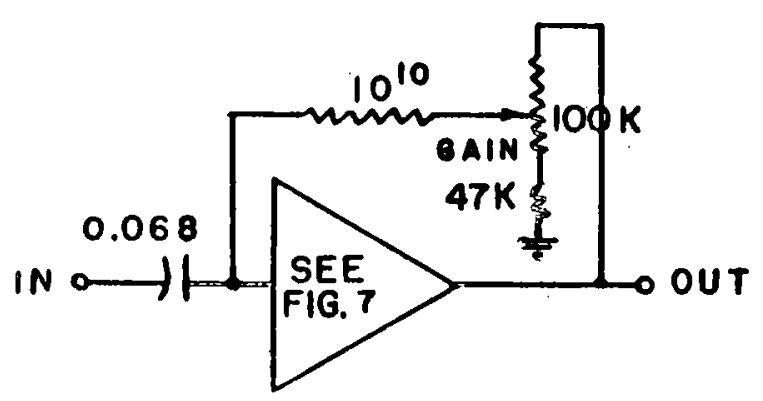

FIGURE 6. Period Meter

KS-25006(b)

Unclassified

\section{Period Amplifier}

As is shown in Figure 6, the period amplifier is a feedback differentlating circuit. This has the usual advantage that with adequate amplification the output is dependent only on passive circuit elements.

In choosing the constants the factors which determine the input current are the log amplifier output per decade, the period to be measured, and the size of the capacitor. With a given capacitor the output voltage depends on the resistor and the time constant on the gain of the amplifier. The values chosen are a compromise in which such factors as camponent size, amplifier stability, current leakage, and time constant are considered. The details of the circult are given in Figure 7.

When the period meter is used for initiating the operation of protective circuits, it is usually desirable to provide a suitable delay before developing a trip signal. This delay may be some function of the period, 


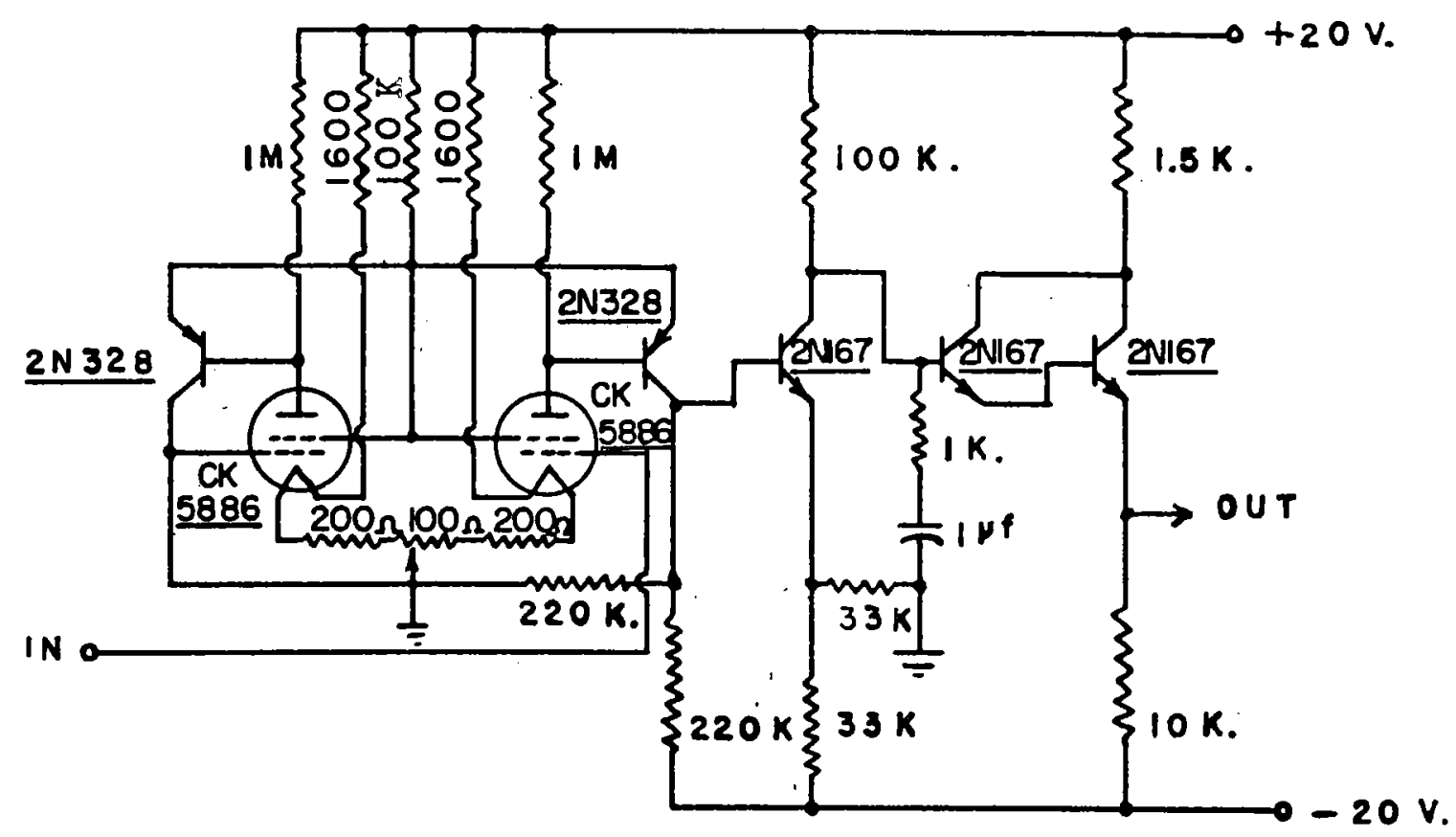

FIGURE 7. Period Amplifier

KS-25007

Unclassified

and on this amplifier the requirement is met by choosing the time constant of the differentiating circuit, which may be expressed as:

$$
\left.T=\frac{R C}{1+A}=\sim 6 \text { sec (with gain }=100\right)
$$

This implies that if a period occurs which is $5 \%$ above the set value, then a trip signal will be generated in $\sim 18 \mathrm{sec}$.

Calibration is made by applying a simulated period from the log amplifier, which is adjusted to be 0.075 volts per doubling time. This gives a steadystate current through the capacitor and feedback resistor of

$$
I=0.075 \frac{\mathrm{C}}{\mathrm{DT}}=3.4 \times 10^{-10} \mathrm{amp}
$$

for $\mathrm{DT}=15 \mathrm{sec}$ (doubling time) and $C=0.068 \mu \mathrm{f}$.

Since the feedback resistor is $10^{10}$ ohms, the output is 3.4 volts and the gain control is adjusted to make the meter read correctly at $15 \mathrm{sec}$ doubling time (4 volts). 


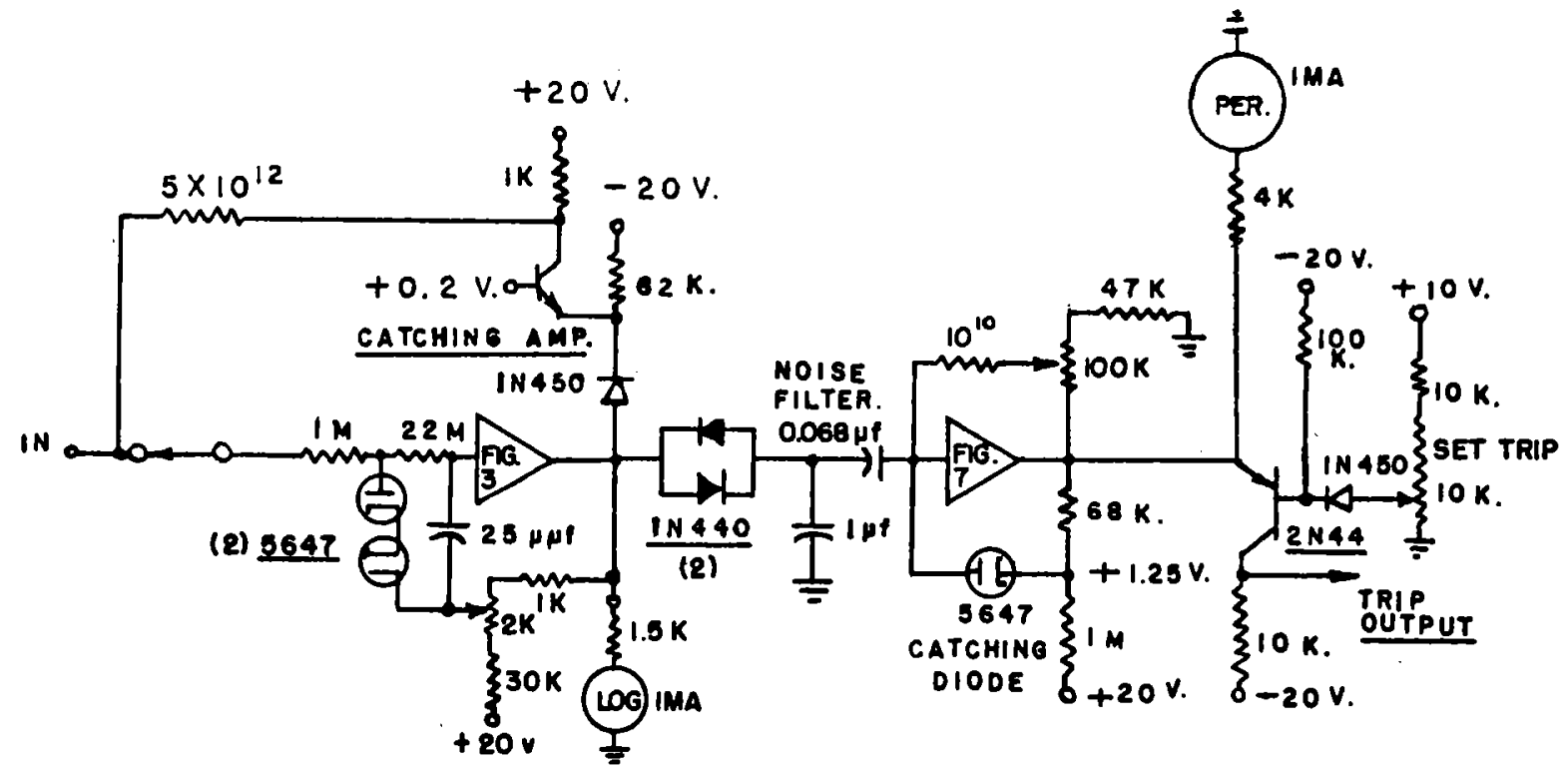

FIGURE 8. Noise Filter - Catching Circuits and Trip Output

KS-25010

Unclassified

\section{Noise Filters}

In order to reduce noise, a nonlinear filter is placed between the output of the log amplifier and the imput to the period anplifier, Figure 8. This filter uses silicon diodes which have a high resistance at low voltage. Two diodes are used in parallel with polarities reversed. With a l- $\mathrm{ff}$ capacitor the filter has a long time constant at low voltages which decreases until it is negligible at potentials above 0.5 volt so that it has little effect on tripping time. At the imput a $1.2 \mathrm{M}$. resistor in series with the log diode also prevents noise transients from being rectified by the diode. The $\mathrm{RC}$ filter at the input grid further reduces the high-frequency gain.

\section{Catching Circuits}

Consider a log amplifier which is operating at very low currents such that the diode is no longer in 1ts logarithmic range or perhaps is cut off as a result of transients or grid current. If now the ion chamber current increases, the output of the amplifier is not logarithmic but linear, simulating a much shorter period, until the log diode reaches its operating range. This effect causes tripping during startup.

In order to prevent this tripping, a negative feedback is used through a resistor from an auxiliary amplifier which is operative only 


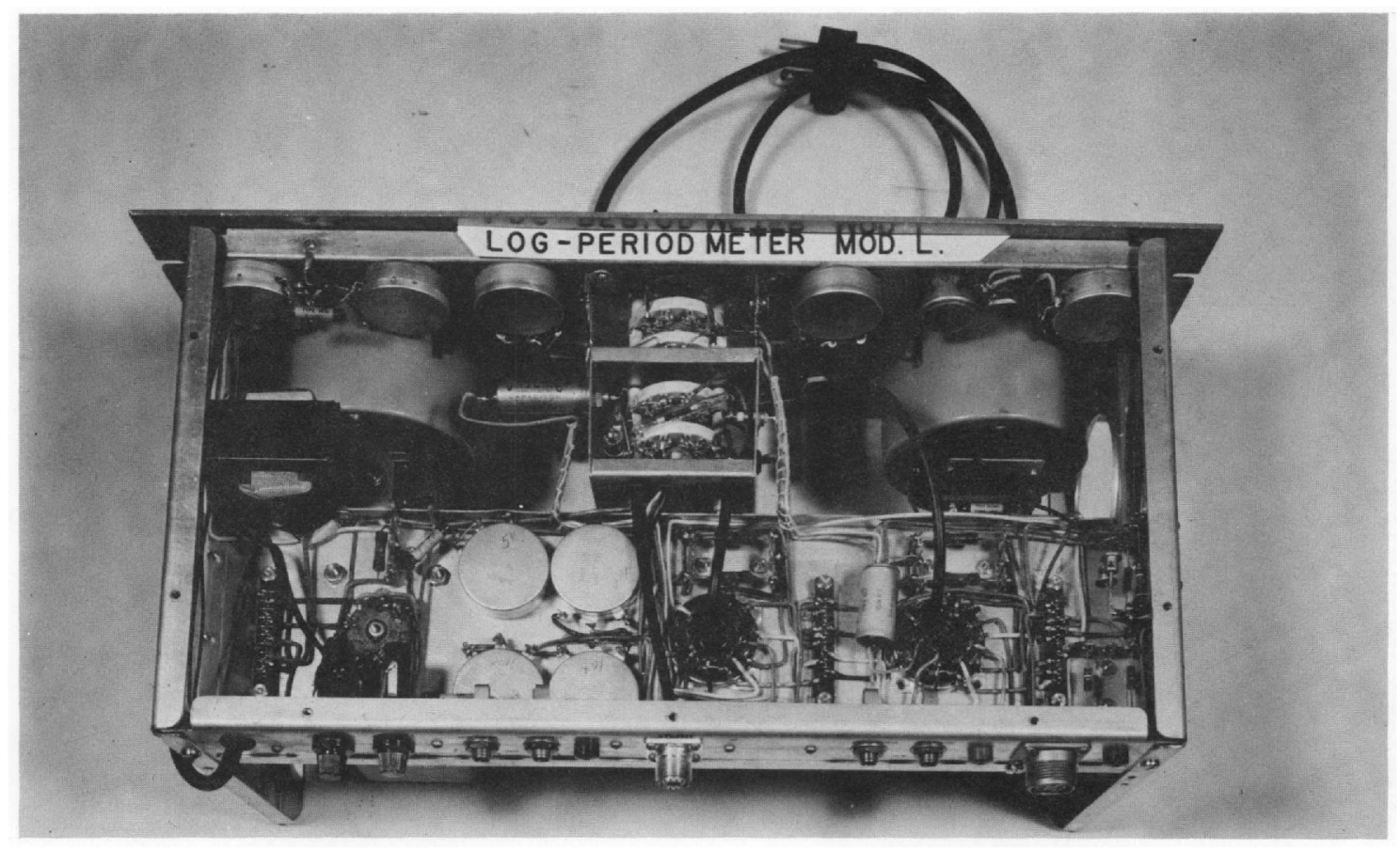

FIGURE 9. Log-Period Meter - Bottom View

KS-21288

Unclassified

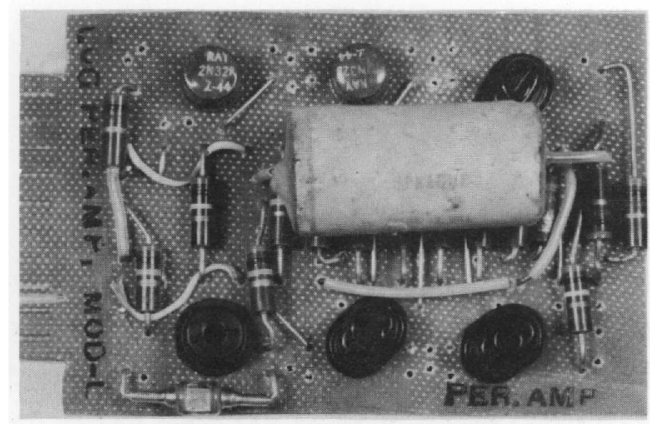

Voltage Regulator

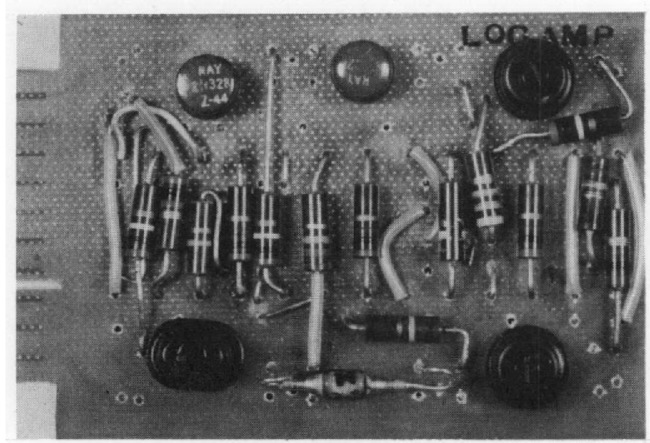

Log Amplifier

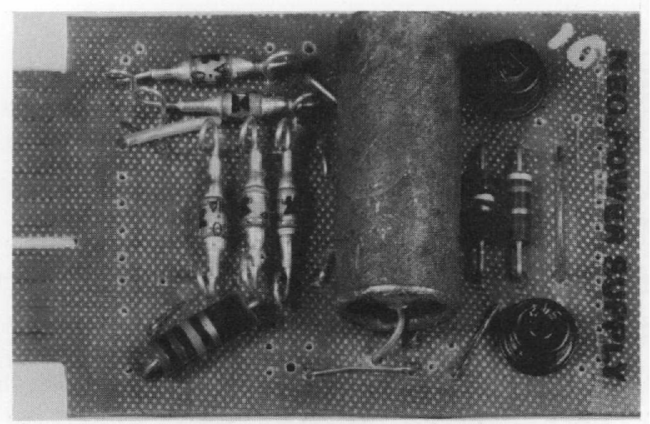

Period Amplifier

FIGURE 10.

Plug-in Circuit Cords

KS-21287

Unclassifiod 


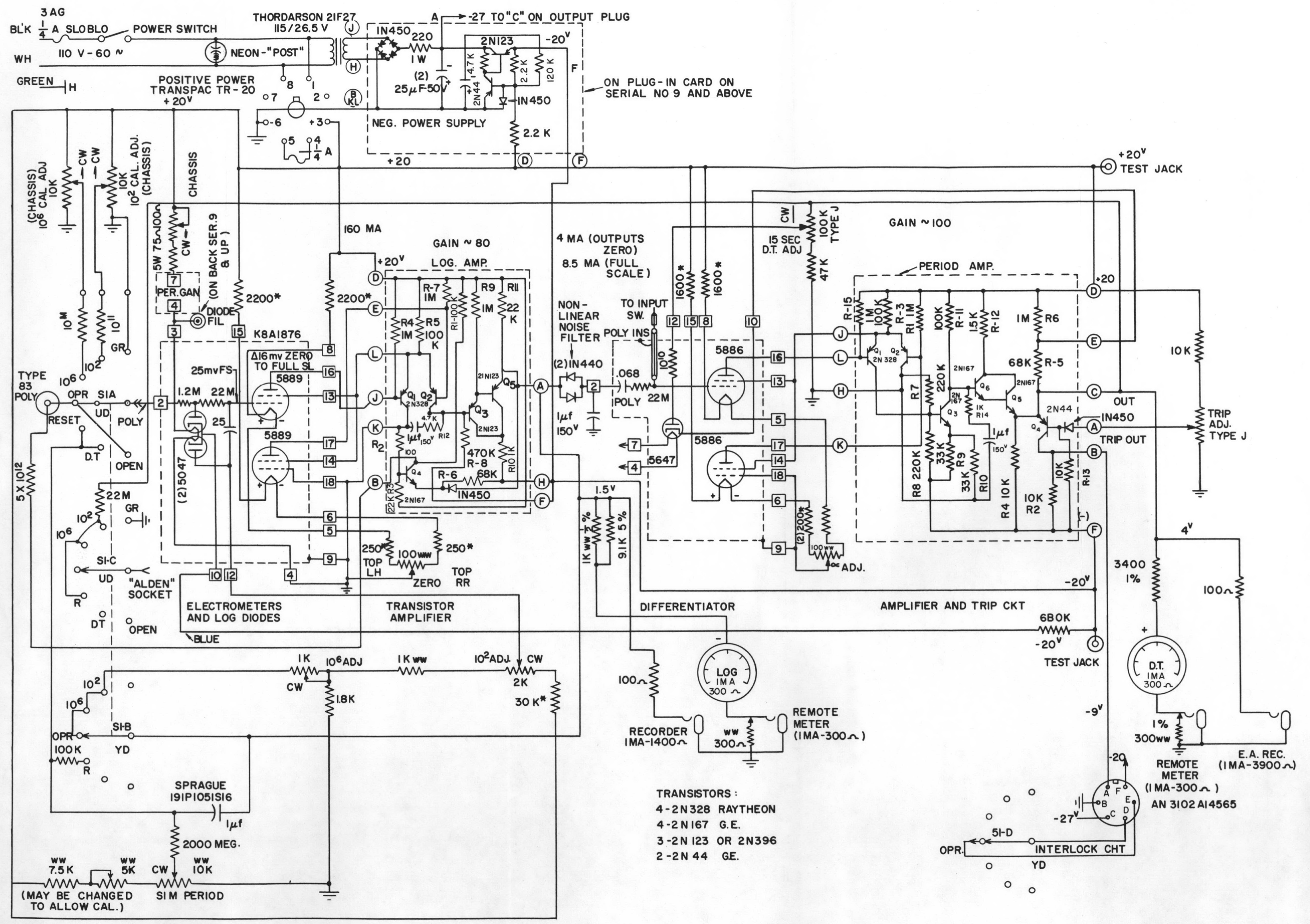

* CARBon FILM

RES $\frac{1}{2}$ WATT AB UNLESS OTHERWISE NOTED

SI- CENTRALAB SERIES 2500-SHIELD DECKS A $Q$ B

WW WIRE WOUND 
FIGURE 11.

Transistorized Log-Period Amplifier 
when the cutput is slightly reversed. This circuit has negligible effect for normal operation, but if the output reverses, indicating the diode current is less than $10^{-12} \mathrm{amp}$, the feedback is activated, which causes a current flow into the input to maintain the current at $10^{-12}$ through the log diode, even with slightly reversed input current. This prevents the log diode from getting out of its logarithmic range.

Similarly, on the period amplifier a catching diode is used as a low impedance feedback to improve the recovery time for input reversals caused by switching transients or negative periods.

\section{Trip Output}

The trip output consists of a discriminator with a transistor biased off by an adjustable potential on its base. The trip circuit ${ }^{6,7}$ generates a current from a positive source, and the trip circuit input must be maintained at a negative potential to prevent tripping. This requirement is met by the current flow to negative 20 volts through the $10 \mathrm{~K}$ resistor. However, when the emitter is driven more positive than the trip setting, the transistor conducts and the output is driven positive, which causes tripping. It will be noted that either grounding or opening the trip output circuit will also cause tripping.

Interlocks are provided on the function switch to guard against moving the switch from the operating position unless the amplifier is disconnected from the trip circuit.

\section{Remote Output and Recorder Circuits}

A jack is provided for remote meters with resistors which are removed to maintain constant circuit impedance. This is desirable because of the low outputs of 1.5 and 4 volts for the logarithmic level and period circuits.

\section{Construction}

The plug-in power supplies, etched circuit cards, and shielded electrometer housings are shown in Figures 9 and 10. The design is arranged for maximum accessibility and ease of servicing. Figure 11 is a diagram of the complete circuit.

\section{CONCLUSIONS}

A number of these amplifiers have been in use for approximately one year with satisfactory operation and no transistor or log diode failures. The only replacements which have been made are 5889 electrometers which were initially used for the log amplifiers. We are considering changing these to the 5886 type, which appears to have a much longer life. 


\section{REFERENCES}

1. Wade, E。 J。, Inst. of Radio Engrs. Convention Record Part 9, 1954, pp. 79-82.

2. Wall, Go F. and Young, M. P., "Naval Research Laboratory Research Reactor.' Part III. An Eight-Decade Logarithmic Amplifier for Nuclear Reactor Instrumentation," NRL-5025, September 5, 1957.

3. Epprecht, G。, Tech Mitt P.T.T., 1951, Pp. 161-7.

4. Goodyear, W. F., "Logarithmic Counting Rate Meter," Electronics 24 (July, 1951), pp. 208-18.

5. De Shong, Jo A., Jr., "Logarithmic Amplifier with Fast Response," Electronics 27 (March, 1954), pp. 190-1.

6. Wade, E. J. and Davidson, D. S., "Application of Transistors to Safety Circuits," Inst. of Radio Engrs. Trans. NS5 (August, 1958), pp. 44-46.

7. Wade, E. J. and Davidson, D. S., "How Transistor Circuits Protect Atomic Reactors," Electronics 21 (July 18, 1958), pp. 73-75. 
